\title{
Coal and plastic waste co-pyrolysis by thermal analysis-mass spectrometry
}

\author{
S. Melendi-Espina ${ }^{\mathrm{a}}$, R. Alvarez ${ }^{\mathrm{b}}$, M.A. Diez ${ }^{\mathrm{b}}$ and M.D. Casal ${ }^{\mathrm{b}}$
}

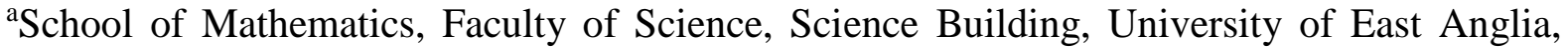
Norwich Research Park, Norwich, NR4 7TJ

bInstituto Nacional Del Carbón (INCAR), CSIC, Apartado 73, 33080 Oviedo, Spain

\section{Abstract}

Simultaneous thermogravimetry-mass spectrometry studies of a pyrolytic decomposition of mixtures of different plastic wastes/coking coal were carried out. The investigation was performed at temperatures up to $1000^{\circ} \mathrm{C}$ in a helium atmosphere under dynamic conditions at a heating rate of $25^{\circ} \mathrm{C} / \mathrm{min}$. Five thermoplastics, commonly found in municipal wastes: low density polyethylene (LDPE), high density polyethylene (HDPE), polypropylene (PP), polystyrene (PS), polyethylene terephthalate (PET) and a plastic mixture rich in polyolefins were selected. Thermogravimetric parameters, together with different characteristic ion fragments from selected libraries of evolving products during the co-pyrolysis process were monitored, such as hydrogen, $\mathrm{CO}_{2}$ and aliphatic and aromatic hydrocarbons. Based on the results obtained, a synergistic effect between coal and individual residues has been found. The maximum interaction occurs at temperatures close to the maximum release of volatile matter of the plastic waste. There is a delay in the decomposition of the plastics that together with the changes in the composition of the volatile matter evolved, promote interactions between the components and have negative effects on coal fluidity. The polyolefinic wastes (HDPE, LDPE and PP) degrade at temperatures close to that of maximum coal degradation, modifying the thermal behaviour of the coal to a lesser degree. However, PS and PET, that release their volatile matter mostly in the early stage of the coal decomposition, show a more pronounced 
influence on the thermal behaviour. Moreover, the kinetic data demonstrates that the addition of polyolefins increases the energy required to initiate pyrolysis compared to PS and PET. All of these results agree with the fact that polyolefins reduce coal fluidity in a more moderate way than PET and PS.

\section{Keywords}

Coal, plastic wastes, co-pyrolysis, TG-MS, evolved gas

\section{Introduction}

Currently co-pyrolysis of single or mixed plastics with fossil fuels (coal and petroleum) are being investigated in order to recover chemicals to partially replace fossil fuels in wellestablished industrial conversion processes and to contribute to the protection of the environment by reducing the volume of waste [1-3]. Among the different routes based on copyrolysis, an environmental friendly alternative is the co-processing of coking coals with plastics from municipal wastes [4-6]. Previous investigations have shown the addition of certain plastic wastes, such as polyolefins, in small amounts $(<5 \%)$ does not affect coke quality $[4,7]$. Therefore, the co-processing of coking coals with plastics from municipal wastes for metallurgical coke production has been implemented at industrial scale $[8,9]$. The composition of the plastic waste added has been shown to be a critical factor in controlling the effect on the coal thermoplastic properties, coking pressure generation during coking process and the structure and properties of metallurgical coke [4, 10-12]. It is well known that the addition of plastic wastes to coal reduces the coal fluidity [11, 13 and 14]. It is important to note that the quality of the obtained coke can be affected by the degree of fluidity reduction. Depending on the different structure and thermal behaviour of the plastics contained in municipal wastes added to coking coals, the opposite effects have been observed. Polyolefins cause a slight 
decrease in fluid coal properties [13-17], improve or maintain coke strength and reactivity and increase the wall pressure generated during coking up to extremely high values [4]. However, aromatic polymers such as PET and PS, which are the strongest modifiers of coal fluidity [14], cause deterioration in coke reactivity towards $\mathrm{CO}_{2}$ and help to balance the wall pressure [1012].

Several researchers have studied co-pyrolysis of coal and plastic waste focusing on the interaction between coal and plastic in order to explain the different effects on the fluidity of the coal [10-14]. Due to the fact that the plastic properties of a coal can be expressed by parameters derived from thermogravimetric analysis (TGA) [18-19], TGA has been used in many works [16-17]. However, few researchers focused on the distribution of the volatile species released [13]. Therefore, the purpose of this paper is to make a contribution in which to further understand the phenomena that cause these fluidity changes, based on TGA and on the distribution of the volatile species evolved. A comparison of the thermal and kinetic behaviours between individual raw materials and the mixtures, by means of TG-MS, has been carried out. The synergistic effect between coal and plastic wastes during pyrolysis has also been studied in order to predict interactions that may occur. To complete the thermal study, different compounds that evolved during the pyrolysis process were studied by spectrometric analysis. These compounds will be important in defining chemical and physical changes of the coal during the pyrolysis, and, therefore, of the different carbonization stages.

\section{Materials and Methods}

\subsection{Raw materials}

An industrial coal blend (PA) used in industrial blast-furnace coke production was selected for preparing the mixtures with several plastics. The main characteristics of this coal blend are shown in Table 1 . The Gieseler maximum fluidity of this coal blend (214 ddpm) is in the 
optimal range of fluidity for coking coals [20]. The maximum fluidity for the coal blend and its mixtures with the different wastes (in an amount of $5 \mathrm{wt} . \%$ ) were measured using a R.B. Automazione PL2000 Gieseler plastometer, following the ASTM D2639 standard procedure (Table 1). Fluidity, in dial divisions per minute (ddpm), as a function of the temperature was measured on a compacted sample ( $5 \mathrm{~g},<0.425 \mathrm{~mm}$ in size), while the sample was heated from 340 to $560{ }^{\circ} \mathrm{C}$ at a heating rate of $3{ }^{\circ} \mathrm{C} / \mathrm{min}$. These data are shown in Figure 1 .

The most common thermoplastics present in municipal wastes were selected in this study and added to the coal in an amount of 5 wt. \%: high and low-density polyethylene (HDPE, LDPE), polypropylene (PP), polystyrene (PS) and polyethylene terephthalate (PET). Additionally, a plastic mixture was also used (PM). The composition of the mixed plastic waste PM rich in polyolefins is 70 wt. \% HDPE, 20 wt. \% PP, $5 \%$ LDPE wt. \%, 5 wt. \% PET and <1 wt. \% cellulose. Proximate and ultimate analyses of the plastic wastes used in this study are described in Table 1. It is worthwhile to note the higher ash content of LDPE. LDPE used in this study comes from agricultural greenhouse films; therefore, its ash content not only comes from the mineral matter present in the plastic waste, but also from any soil contamination.

LDPE, HDPE, PP and PS were supplied by REPSOL-YPF while the plastic mixture was provided by the Spanish recycling company Abornasa.

In the text, the coal blend is mostly referred to simply as coal, and coal/plastic mixture refers to the mixture of the coal blend with a plastic waste.

\subsection{Thermogravimetric analysis}

The powdered samples of the coal, individual plastic wastes and different coal/plastic mixtures were subjected to TGA in a simultaneous TA Instrument SDT2960 analyser. About $7 \mathrm{mg}<$ $0.212 \mathrm{~mm}$ size of the individual plastic wastes were heated from room temperature up to 600 ${ }^{\circ} \mathrm{C}$ at a heating rate of $25{ }^{\circ} \mathrm{C} \mathrm{min}-1$ using helium as a carrier gas in order to sweep out the 
volatile products (flow rate $100 \mathrm{ml} / \mathrm{min}$ ). For the coal and coal/plastic mixtures, the final temperature of the TGA was $1000^{\circ} \mathrm{C}$. The following parameters are derived from this test; on one hand the temperature at which the maximum release of volatile matter takes place on the basis of the DTG curves (Tmax); and on the other hand the initial and final temperatures of the carbonization process (temperatures at $2 \%$ and $98 \%$ of conversion respectively).

Thermogravimetric-mass spectrometric analysis (TG-MS) of the coal/plastic mixtures were carried out by coupling a quadrupole mass spectrometer (Balzers, Thermostar GSD-300T) to the thermobalance. A fused silica transfer line heated at $200{ }^{\circ} \mathrm{C}$ was used to avoid condensation. The evolution of the temperature of the evolved gaseous products and the intensity of the selected ion fragments were monitored together with the thermogravimetric parameters at different times.

\subsection{Kinetic study}

The kinetic parameters, activation energy and pre-exponential factor of coal and plastic wastes pyrolysis were determined by the integral method. It is assumed that solid fuel pyrolysis is a first order reaction. This assumption has been done in previous studies with coal, biomass or plastics [21-26].

Therefore, the devolatilization rates to be determined follow first-order reaction based Arrhenius theory and so the kinetics of the reaction are described as:

$\mathrm{dx} / \mathrm{dt}=\mathrm{A} \exp (-\mathrm{E} / \mathrm{RT}) \quad$ eq $(1)$

Where $\mathrm{A}$ is a pre-exponential factor $\left(\mathrm{min}^{-1}\right), \mathrm{E}$ is activation energy $(\mathrm{J} / \mathrm{mol}), \mathrm{R}$ is the universal gas constant $\left(\mathrm{R}=8.314 \mathrm{Jmol}^{-1} \mathrm{~K}^{-1}\right), \mathrm{T}$ is the thermodynamic temperature $(\mathrm{K})$ and $\mathrm{x}$ is the pyrolysis conversion, which can be calculated as follows:

$\mathrm{x}=\left(\mathrm{m}_{0}-\mathrm{m}_{\mathrm{t}}\right) /\left(\mathrm{m}_{0}-\mathrm{m}_{\mathrm{f}}\right) \quad$ eq $(2)$ 
Where $\mathrm{m}_{0}$ is the initial mass of the sample, $\mathrm{m}_{\mathrm{t}}$ is the sample mass at time $\mathrm{t}$ during the thermal degradation and $\mathrm{m}_{\mathrm{f}}$ is the final mass at the end of the pyrolysis.

For a constant heating rate, $\beta$, during pyrolysis, $\beta=\mathrm{dT} / \mathrm{dt}$; Therefore, eq (1) after integration can be transformed into:

$\ln \left(-\ln (1-\mathrm{x}) / \mathrm{T}^{2}\right)=\ln (\mathrm{AR} / \beta \mathrm{E}(1-2 \mathrm{RT} / \mathrm{E}))-\mathrm{E} / \mathrm{RT} \quad$ eq $(3)$

It can be demonstrated that for most values of $\mathrm{E}$ and for the temperature range of the pyrolysis, the expression ln $(\mathrm{AR} / \beta \mathrm{E}(1-2 \mathrm{RT} / \mathrm{E}))$ in $\mathrm{Eq}(3)$ is constant. Therefore, if the left side of the eq (3) is plotted versus $1 / \mathrm{T}$, a straight line can be obtained. The activation energy, E, can be calculated from the slope of the line, E/R. In addition, the pre-exponential factor, A, can be calculated from the y-intercept of the line.

\section{Results and discussion}

\subsection{Thermal behaviour of the coal and the coal-plastic mixtures}

Figure 2 shows the DTG curves of the plastic wastes that were tested and Table 2 summarizes the initial and final temperatures of volatile matter (VM) released ( $\mathrm{T}$ initial and $\mathrm{T}$ final respectively) and the temperature at which the maximum release of VM takes place (Tmax) on the basis of the DTG curves.

Plastic wastes differ in their thermostability; their mass loss occurs in a single step and in a narrow temperature range. Polyolefins (HDPE, LDPE and PP) have the narrowest decomposition temperature ranges (lower than $90{ }^{\circ} \mathrm{C}$, Table 2), whereas the degradation of PS and PET and the blend PM shows a wider temperature interval $\left(>100{ }^{\circ} \mathrm{C}\right)$.

The degradation starts between $380{ }^{\circ} \mathrm{C}$ for PS and $436{ }^{\circ} \mathrm{C}$ for LDPE and finishes at a temperature between $483^{\circ} \mathrm{C}$ for PS and $513{ }^{\circ} \mathrm{C}$ for LDPE. Thermal degradation of plastic wastes, under the experimental conditions applied, yields a small amount of residue (less than 8 wt. \%). However, PET generates higher amount of solid waste, 17.4 wt. \%. Additionally, it 
is important to note that the LDPE solid product (7.6 wt. \%) is higher if it is compared with the other two polyolefins. This fact is related to its origin. This residue comes from agriculture, and as mentioned above, it contains a small amount of inorganic material that remains as solid waste after pyrolysis.

The temperature of maximum evolution of pyrolysis products (Tmax) of single plastics varies in the following order: $\mathrm{PS}<\mathrm{PET}<\mathrm{PP}<\mathrm{LDPE}<\mathrm{HDPE}$ (Table 2). Tmax shows that the decomposition of plastic wastes is determined by the links of the polymer chain. Thus, polymers such as polyethylene (LDPE and HDPE) are more thermally stable (higher Tmax) than those containing ethylene groups replaced by methylene (PP) or phenyl groups (PS) and also by units containing oxygenated groups and p-phenyl (PET).

The plastic blend, PM, shows an asymmetric DTG peak with a Tmax at $466^{\circ} \mathrm{C}$, corresponding to polyolefins present in its composition. The volatile matter released up to $400^{\circ} \mathrm{C}$ corresponds to the degradation of cellulose. The position of the DTGmax of the plastic mixture PM, is slightly lower than would be expected from its composition (70 wt. \% HDPE, 20 wt. \% PP, 5 wt. \% LDPE and 5 wt. \% PET). The Tmax value is located between PP $\left(475^{\circ} \mathrm{C}\right)$ and PET (449 $\left.{ }^{\circ} \mathrm{C}\right)$ (Table 2). This may be due to interactions between different polymers of the residue leading to a faster decomposition rate during the pyrolysis.

The DTG curves of the coal PA and their mixtures with the different plastic wastes are shown in Figure 3. Coal and the plastic wastes behave differently (Figure 2 and 3). As it is shown in Table 3, thermal degradation of coal starts at temperatures below those of plastic wastes $\left(286^{\circ}\right.$ C), and decomposes in a wider temperature range $\left(661^{\circ} \mathrm{C}\right)$. In addition, the DTG profile of the coal shows a main peak at $505{ }^{\circ} \mathrm{C}$, which is also shown in blends containing the three polyolefins (HDPE, LDPE and PP) (Figure 3).

Under the pyrolysis conditions applied, polyolefins have the narrowest decomposition temperature ranges with a Tmax inside the thermal degradation of the macromolecular network 
of the coal, whereas the degradation of PS and PET takes place close to the early stages of coal decomposition (Table 2 and 3). An examination of the DTG profiles of the mixtures shows that blends with HDPE, LDPE and PP present a single peak at a temperature slightly lower than that of the coal PA (495-499 vs. $505^{\circ} \mathrm{C}$ ). However, when PS and PET are added to coal, these mixtures present a bimodal evolution of volatiles, with the first peak being attributed to plastic decomposition and the high-temperature peak to coal devolatilization.

When comparing the profiles of the coal/plastic mixtures and the corresponding plastic, a shift in the evolution of volatiles towards a higher temperature can be clearly observed (Table 2 and 3). This suggests that some degree of physical and chemical interaction may occur during the co-pyrolysis of plastics with coal $[5,15]$.

The presence of plastic wastes in the mixtures adversely affects coal thermoplasticity. Figure 1 shows that Gieseler maximum fluidity of coal decreases with the presence of plastic wastes. The presence of PS and PET strongly reduces coal fluidity (Figure 1). Interactions responsible for these alterations may be physical or chemical. Physical interactions can occur by reducing internal plasticity of the components of coal [5], while chemical interactions include hydrogen transfer reactions, causing fluidity decrease if the additive is hydrogen acceptor [15].

In order to study these interactions between plastic waste and coal, the weight loss during the co-pyrolysis was estimated from individual thermal behaviour of coal and the different plastic wastes. Figure 4 shows the difference between the values of the loss mass experimental and estimated $(\Delta \mathrm{W})$, expressed in percent, in the course of the co-pyrolysis. For all the mixtures, $\Delta \mathrm{W}$ is practically constant (less than $0.4 \%$ ) up to $400^{\circ} \mathrm{C}$, as the plastics and coal have hardly begun to decompose and therefore there are no possible interactions between them.

In all mixtures, a significant interaction is observed between 400 and $530{ }^{\circ} \mathrm{C}$, while the last stage of degradation $\left(\mathrm{T}>530^{\circ} \mathrm{C}\right)$ is less affected. These results mean that the highest interaction between coal and plastic waste is produced next to the temperatures of maximum volatile 
matter evolution of plastic residues. Temperatures corresponding to the maximum $\Delta \mathrm{W}$ are always higher than the Tmax decomposition of the individual plastics, which also suggests a delay in the evolution of volatile matter. This is in agreement with previous results $[4,13]$ where after the examination of the semicokes by SEM, it was deduced that the degradation of some plastics such as, LDPE, HDPE, PP and PET present in the blend with coal was delayed, affecting the volatile matter release. The variations for the polyolefins (HPDE, LDPE and PP) are less pronounced; however, they are clear in the case of PS, PET and PM. According to Figure 4, maximum for the mixtures of coal with PS, PET and PM are 443,456 and $480^{\circ} \mathrm{C}$ respectively, whereas the Tmax values for each individual plastic are $441{ }^{\circ} \mathrm{C}$ (PS), $449{ }^{\circ} \mathrm{C}$ (PET) and $466^{\circ} \mathrm{C}(\mathrm{PM})$ (Table 2).

PM shows the highest difference of weight loss percentage, between experimental and theoretical ones. The synergistic effect for the plastic mixture is higher than that for the single plastic wastes.

PP is the polyolefin that shows the maximum interaction during the co-pyrolysis. This can be due to the fact that $\mathrm{PP}$ has additional $\mathrm{CH}_{3}$ groups, which decrease the thermal stability of the plastic, affecting the breaking of $\mathrm{C}-\mathrm{C}$ bonds.

The results indicate that there is a synergism between coal and plastic waste during copyrolysis. The mechanism of this synergistic effect is not very clear. It seems that when plastic decomposition via radical chain reactions occurs close to the early stages of the decomposition of the coal macromolecular network, there is greater opportunity for the small size species from coal decomposition to volatilize and then to be stabilized by hydrogen transfer or cross-linking reactions. These small species are responsible for the development and maintenance of coal fluidity. As a consequence of the stabilization of these molecules, the fluidity decreases drastically. PS and PET are good examples of strong modifiers of coal thermal behaviour [1517, 27]. They decrease the fluidity of the coal and give rise to more disordered carbon structures 
in the semicokes [5, 13, 15, 28 and 29]. However, if the degradation products of the plastics are evolved close to the range of maximum evolution of volatiles from the coal, when the maximum amount of gas and tar is produced and solidification sets in, the decomposition products from plastic will be trapped in the co-pyrolysis system and, then, incorporated into the semicoke [4, 11, 14 and 15]. As observed in the TGA, this behaviour is exhibited by the polyolefins, which overlap over a wide interval of coal degradation.

\subsection{Kinetic parameters}

Table 4 shows the kinetic parameters and their correlation coefficients for the individual plastic wastes and the mixture, PM. For the plastic wastes, the pyrolysis process can be described by one first order reaction (Table 4) with correlation factors $\left(\mathrm{R}^{2}\right)$ between 0.993 and 0.999 . However, for PA and its mixtures with the different plastic wastes, the process can be described as four consecutive first order reactions, as it is shown in Figure 5.

The three polyolefins (HDPE, LDPE and PP) present an activation energy ranging between 303 and $322 \mathrm{~kJ} \mathrm{~mol}^{-1}$, while the activation energy for PS and PET is lower (247 and $274 \mathrm{~kJ}$ mol $^{-1}$, respectively) (Table 4). This is in agreement with the thermogravimetric results that show that polyolefins are more stable in thermal degradation than PS and PET due to the presence of oxygen atoms and/or aromatic structures in the composition of these last two plastics. The plastic blend PM presents the lowest activation energy, $190 \mathrm{~kJ} \mathrm{~mol}^{-1}$, although its main component is the HDPE, which presents the highest activation energy. This lower activation energy reflects the interaction that exists between the different components of the residue. It is possible that the less stable polymer causes destabilization of the more stable polymer. Miranda et al [30] conclude that when the E of the plastics is similar, the behaviour of the plastic blend results in a decrease of the $\mathrm{E}$ of the more stable polymers due to a hydrogen transfer from the more stable polymer towards the radical of the less stable polymers. 
Figure 5 shows the pyrolysis mechanisms of the coal PA $\left(\operatorname{Ln}\left(-\ln (1-\mathrm{x}) / \mathrm{T}^{2}\right)\right.$ vs. $1 / \mathrm{T}$. This process can be divided in four consecutive first-order reactions. In this work, the kinetic parameters of the different stages were obtained individually with the conversion, $\mathrm{x}$, calculated for each stage. Table 5 shows the kinetic parameters of the coal and its mixtures with the different plastic wastes.

It is difficult to describe all of the mechanisms involved in the coal pyrolysis. The highly heterogeneous nature of the coal results in multiple heterogeneous chemical reactions. Therefore, a general description of each regime will be given. In the first stage (temperature < $210^{\circ} \mathrm{C}$ ), the coal releases water. After that, at temperatures between 215 and $409{ }^{\circ} \mathrm{C}$, the preplastic stage takes place. The three-dimensional structure of carbon starts to open (pore formation) and gas starts to be released from the coal, as $\mathrm{CO}_{2}, \mathrm{H}_{2}$ and other low molecular weight hydrocarbons. At these low temperatures almost no weight loss occurred and the activation energy is low (56 and $59 \mathrm{~kJ} / \mathrm{mol}$ ) (Table 5). Between 414 and $525^{\circ} \mathrm{C}$ the key step in the carbonization process occurs, called the plastic stage of the coal. In this key stage the coal starts to soften. The fluidity of the system increases with the temperature until it reaches a maximum value. The enhanced mobility of the molecules results in intermolecular condensation reactions of aromatic compounds. In this plastic stage, the volatile matter is mainly composed by condensable gases (tar) and non-condensable gases $\left(\mathrm{CO}, \mathrm{CO}_{2}\right.$ and light hydrocarbons, mainly $\mathrm{CH}_{4}, \mathrm{C}_{2} \mathrm{H}_{6}$ and $\mathrm{C}_{2} \mathrm{H}_{4}$ ). It must be taken into account that during this period the coal suffers the highest mass loss (Figure 3) and the main properties of the resultant coke are determined at this stage. This stage presents the highest activation energy $(194 \mathrm{~kJ} / \mathrm{mol})$ and pre-exponential factor (2.1 E+14) (Table 5).

After maximum fluidity attained, the viscosity increases and coal resolidifies into semicoke that with further pyrolysis, transforms into high-temperature coke. During this last stage (530$986^{\circ} \mathrm{C}$ ) the condensation of higher molecular weight substances to yield coke takes place in 
addition to the elimination of hydrogen, which is also released as gas from the coal particle. The activation energy shows the lowest value $(28 \mathrm{~kJ} / \mathrm{mol})$.

Similar results were obtained when $\ln \left(-\ln (1-\mathrm{x}) / \mathrm{T}^{2}\right)$ was plotted vs. $1 / \mathrm{T}$ for the coal/plastic mixtures selected. As an example, Figure 6 shows the graphs obtained for the PA-5LDPE and PA-5PS. It seems that for the coal/plastic mixtures, the pyrolysis mechanism is dominated by the main component, the coal PA. Activation energies of the first two stages and the last one for the coal/plastic mixtures, suffer almost no variations with regard to coal activation energy (Table 5). This is due to the fact that during these stages the main weight loss comes from the coal. However, some differences are shown in the third stage (Table 5) and therefore differences in the mechanism that controls the co-pyrolysis. As it was mentioned before, during this stage the main chemical reaction that will affect the final product obtained, takes place. The energy required to start the pyrolysis reactions of coal/polyolefin mixtures is higher than that for the blends coal/PS and coal/PET.

The activation energies for the mixtures of the coal with PS and PET are even lower than that for the coal PA (194 kJ/mol vs $170 \mathrm{~kJ} / \mathrm{mol}-163 \mathrm{~kJ} / \mathrm{mol}$ ) (Table 5). Therefore, the presence of PS and PET in the blend promotes the pyrolysis coal reaction.

When the mixture PM is added to the coal, the activation energy $(209 \mathrm{~kJ} / \mathrm{mol})$ is higher than the required energy of the individual coal $(194 \mathrm{~kJ} / \mathrm{mol})$ and the individual residue PM (190 $\mathrm{kJ} / \mathrm{mol}$ ). This agrees with the existing synergism.

\subsection{Thermogravimetric-mass spectrometric analysis (TG-MS)}

The interactions between the coal and plastics are also influenced by the chemical composition of the volatile matter. By means of TG-MS analysis it is possible to study how the presence of plastic waste affects the volatile species evolved during co-pyrolysis (non-condensable, such as, $\mathrm{H}_{2}, \mathrm{CO}_{2}$, or light hydrocarbons). Therefore, a comparison has been made between gas 
products from the coking coal PA (reference sample) and the gas products released by the coal/plastic mixtures.

The ion fragment signals presented in Table 6 represent different families of compounds that were monitored during the co-pyrolysis. Table 7 shows the maximum evolution temperature for the fragments monitored, for the coal PA and for the different coal/plastic mixtures.

Due to the complexity of the evolved gas products, a semi-quantitative analysis based on the comparison of the integrated peak areas of the species monitored was carried out.

Figure 7 shows the DTG curve of the coal, the evolution of the methane, followed by $\mathrm{m} / \mathrm{z} 15$, and the evolution of the hydrogen $(\mathrm{m} / \mathrm{z} 2)$. Methane and hydrogen are the non-condensable gaseous products produced in greater proportion. Above $450{ }^{\circ} \mathrm{C}$, methane is the most abundant hydrocarbon during the pyrolysis of the coal and its mixtures with plastics. Methane generation, followed by $\mathrm{m} / \mathrm{z} 15$, is due to dealkylation reactions of the carbonaceous matrix and hydrocarbon chains from the polymers. It is accompanied by the release of other aliphatic and aromatic hydrocarbons.

The temperature of maximum evolution of hydrogen, $\mathrm{m} / \mathrm{z} 2$, occurs in a narrow temperature range between 782 and $789^{\circ} \mathrm{C}$ (Table 7), regardless the plastic residue added. Hydrogen release is due to the aromatic condensation, polymerization reactions and the decomposition of heterocyclic compounds that occur in the post-plastic and consolidation stages, from 500-1000 ${ }^{\circ} \mathrm{C}[31]$.

Paraffinic and olefinic fragments evolve in the temperature range between 498 to $553{ }^{\circ} \mathrm{C}$ (Table 7). The temperature of maximum evolution of the paraffinic and olefinic fragments differs depending on the plastic waste added to the blend. For the alkyl fragments, in general this temperature slightly decreases as the number of carbon atoms present in the hydrocarbon increases. In most of the blends containing plastics, the maximum temperature of hydrocarbons occurs at lower temperatures than that for the coal PA (Table 7). 
There are not significant variations in the maximum temperature of evolution of aromatic fragments followed by the ions $\mathrm{m} / \mathrm{z} 77,78$ and 91 , with the exception of the mixture with PS. In this sample the release of the aromatic fragments takes place at lower temperatures than those of the coal $\left(468-471{ }^{\circ} \mathrm{C}\right.$ vs $\left.508-518^{\circ} \mathrm{C}\right)$ (Table 7).

When the composition of the light pyrolysis products from the coal and its mixtures with plastics are compared, some relevant features are shown. These results are derived from the normalised areas of the corresponding peaks to that of hydrogen. The addition of plastics to the coal (i) promotes an increase of the amount of hydrogen with respect to that of methane, which indicates greater aromatic condensation and intra- and intermolecular rearrangements; (ii) promotes a higher amount of aliphatic compounds from $\mathrm{C}_{2}$ to $\mathrm{C}_{4}$ in the form of both alkanes and alkenes; (iii) and also promotes a higher ratio of paraffin/olefin, with the exception of the PA5PS mixture (Figure 8).

As a consequence of the polymer structure, blends made up of PS and PET behave in a different way to polyolefins. Mixtures with PS and PET (polymers containing aromatic rings in their structure) increase the proportion of aromatic fragments, especially in the case of PS. This is because their main degradation products are styrene and ethylbenzene [32]. While the addition of polyolefins promotes an increase of aliphatic compounds. This is confirmed by the relationships between the fragments from saturated hydrocarbons $(43,57)$ and those from aromatic structures $(77,78,91)$ (Figure 9).

Therefore, the addition of polyolefin wastes favours the formation of saturated hydrocarbons and unsaturated short chain (number of $\mathrm{C}$ atoms $\leq 5$ ) that become part of the gas or tar. A higher content of $\mathrm{C}_{1}-\mathrm{C}_{4}$ hydrocarbons in the gas increases its calorific value [33].

As expected, the addition of oxygen-containing polymers such as PET increases the $\mathrm{CO}_{2}$ content in the gas (Figure 10) that is released at low temperatures of approximately 465 and $633^{\circ} \mathrm{C}$. 
PS also produces $\mathrm{CO}_{2}$ despite not having oxygen in its composition. This polymer negatively affects the development of coal fluidity [10, 14 and 29] causing crosslinking reactions between oxygen function in the early stages of the pyrolysis process.

\section{Conclusions}

The thermal degradation of additives added to the coal varies according to its nature, structure and composition, as reflected in the temperature of maximum evolution of volatile matter and on the decomposition temperature ranges.

It seems that there is a synergistic effect between coal and individual residues. In general, the co-pyrolysis process seems to be faster, occurring in a narrower temperature range. The maximum interaction between the coal and plastics occurs close to the temperature at which maximum release of plastic volatile matter takes place. Additionally, a delay in the evolution of volatile species from the plastics is observed when they are blended with the coal.

The shift of the evolution of volatiles from plastics toward higher temperatures, and therefore the greater overlap between coal and residues, may explain the fluidity reduction caused by the addition of plastic wastes. Polyolefins degrade at temperatures close to the degradation of the three-dimensional structure of coal, modifying to a lesser degree the thermal behaviour of the coal. However, PS and PET degradation occurs at the early stage of coal decomposition, having a more pronounced effect. Moreover, the kinetic data demonstrates that the activation energies for the polyolefins pyrolysis are higher than those for PS and PET. These results are coherent with previous results that show polyolefins reduce coal fluidity in a more moderate way than PS and PET [13-14].

On the other hand, the relative proportion and the temperature of emission of light gases such as hydrogen, methane, aliphatic hydrocarbons with up to four carbon atoms (including paraffin and olefin pairs), aromatic hydrocarbons and carbon dioxide is consistent with the functional 
groups of the plastic added to the coal. The thermal events during co-pyrolysis and the chemical families of compounds in the gas are in agreement with the modification of the coal fluidity, the degree of ordering of the carbon structure of the semicokes and the evolution of gas pressure during the coking process.

\section{Acknowledgements}

The financial support provided by the Ministerio de Ciencia e Innovación through project CTM2004-03254 is gratefully acknowledged. The authors would like to thank Mr. Christopher Morris for his assistance. 
Figure 1. Gieseler maximum fluidity of the coal and the coal/plastic mixtures.

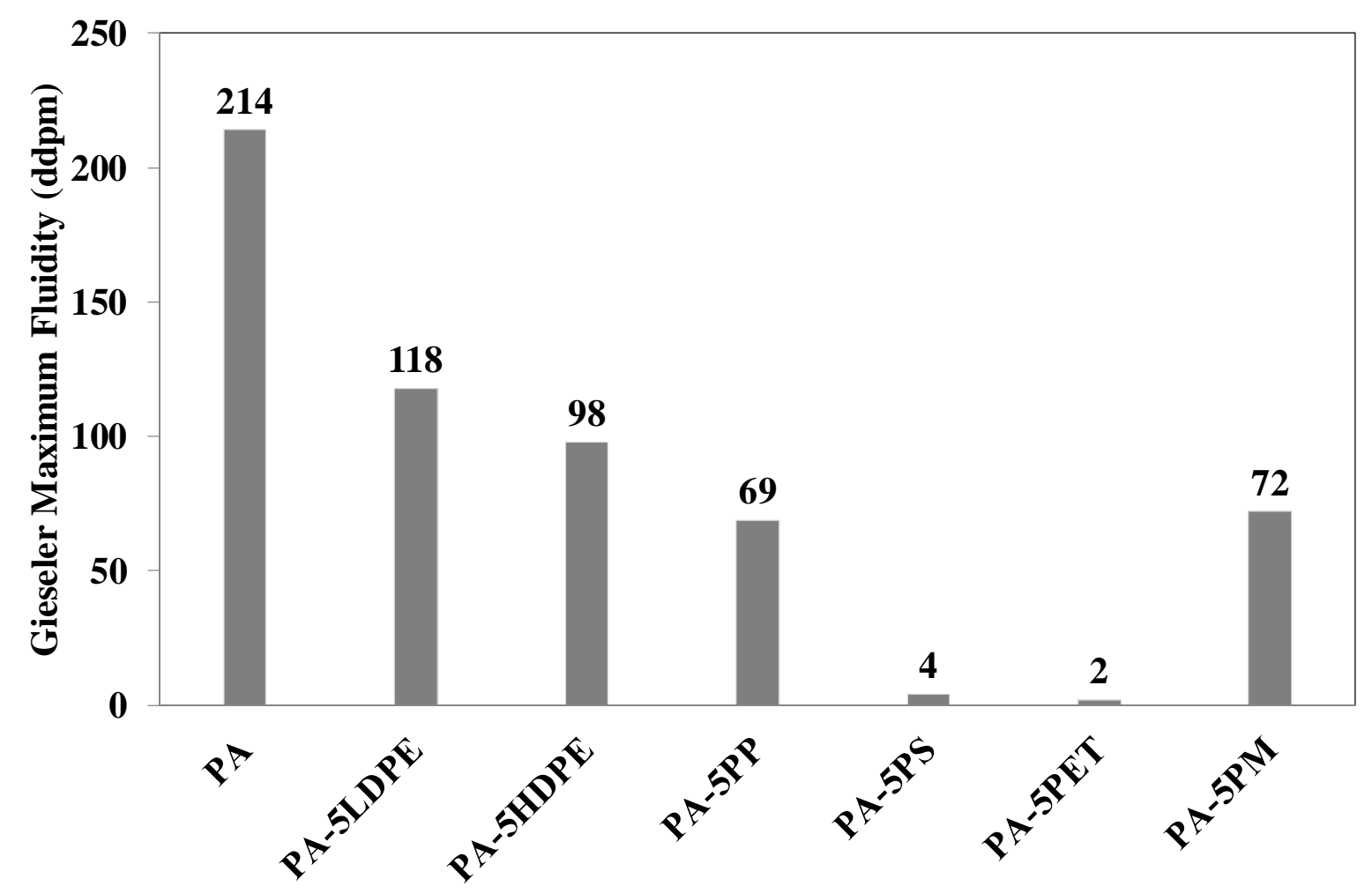


Figure 2. DTG curves of the plastic wastes

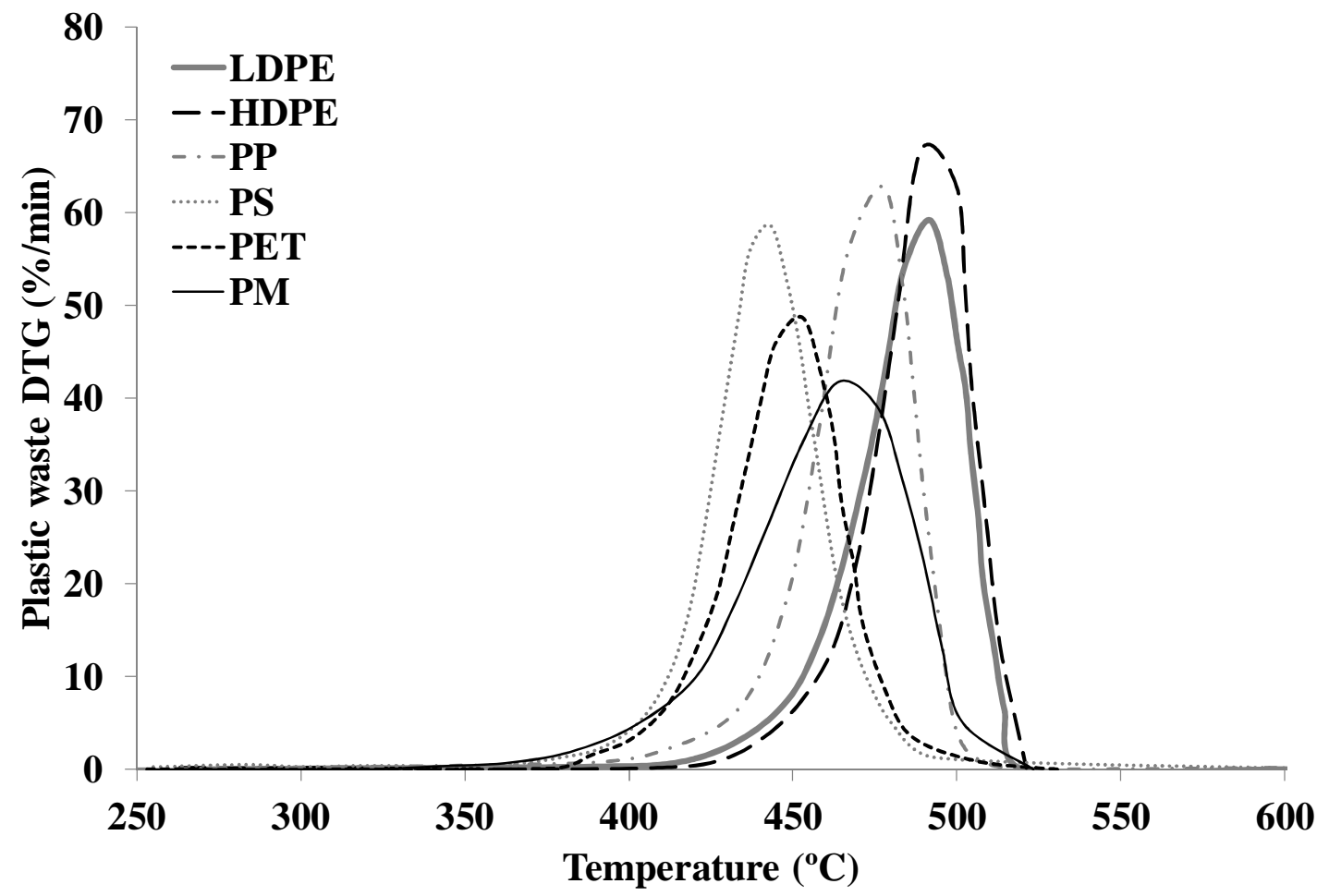


Figure 3. DTG curves of the coal (PA) and the coal/plastic mixtures

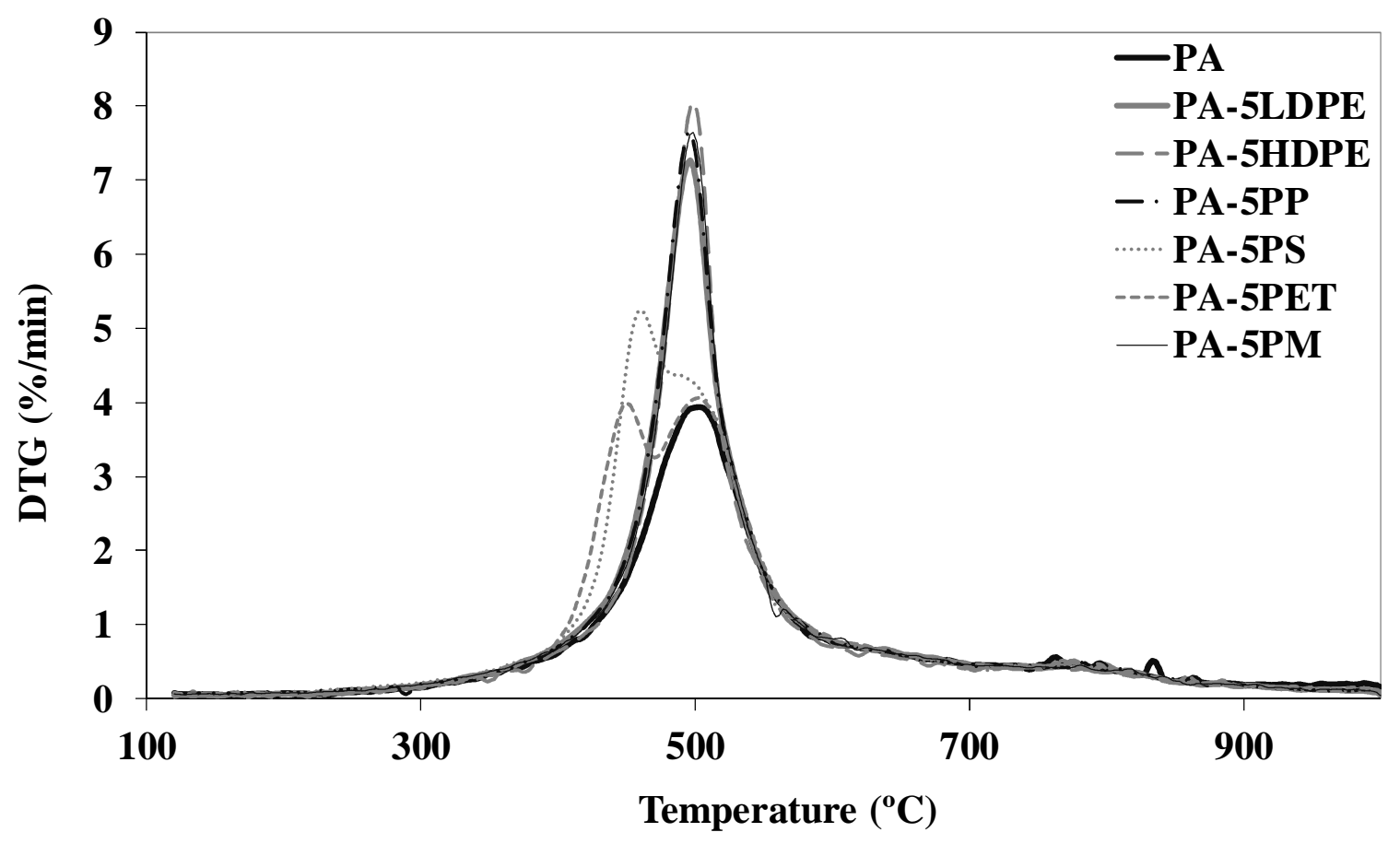


Figure 4. Variation of the differences between experimental mass loss and calculated data $(\Delta \mathrm{W})$ for coal/plastic mixtures

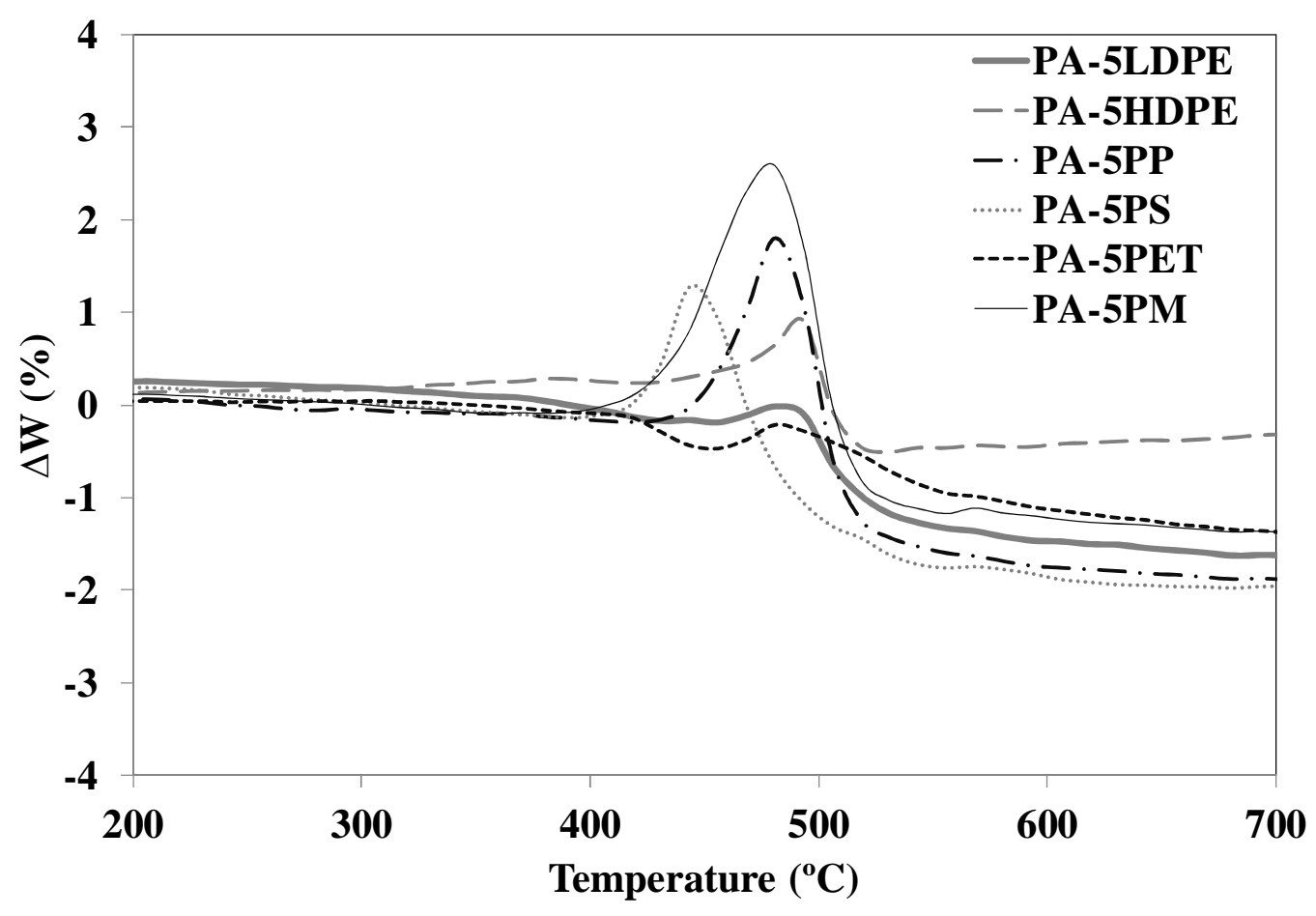


Figure 5. Plot of $\ln \left(-\ln (1-\mathrm{x}) / \mathrm{T}^{2}\right)$ against $1 / \mathrm{T}$ for the coal (PA)

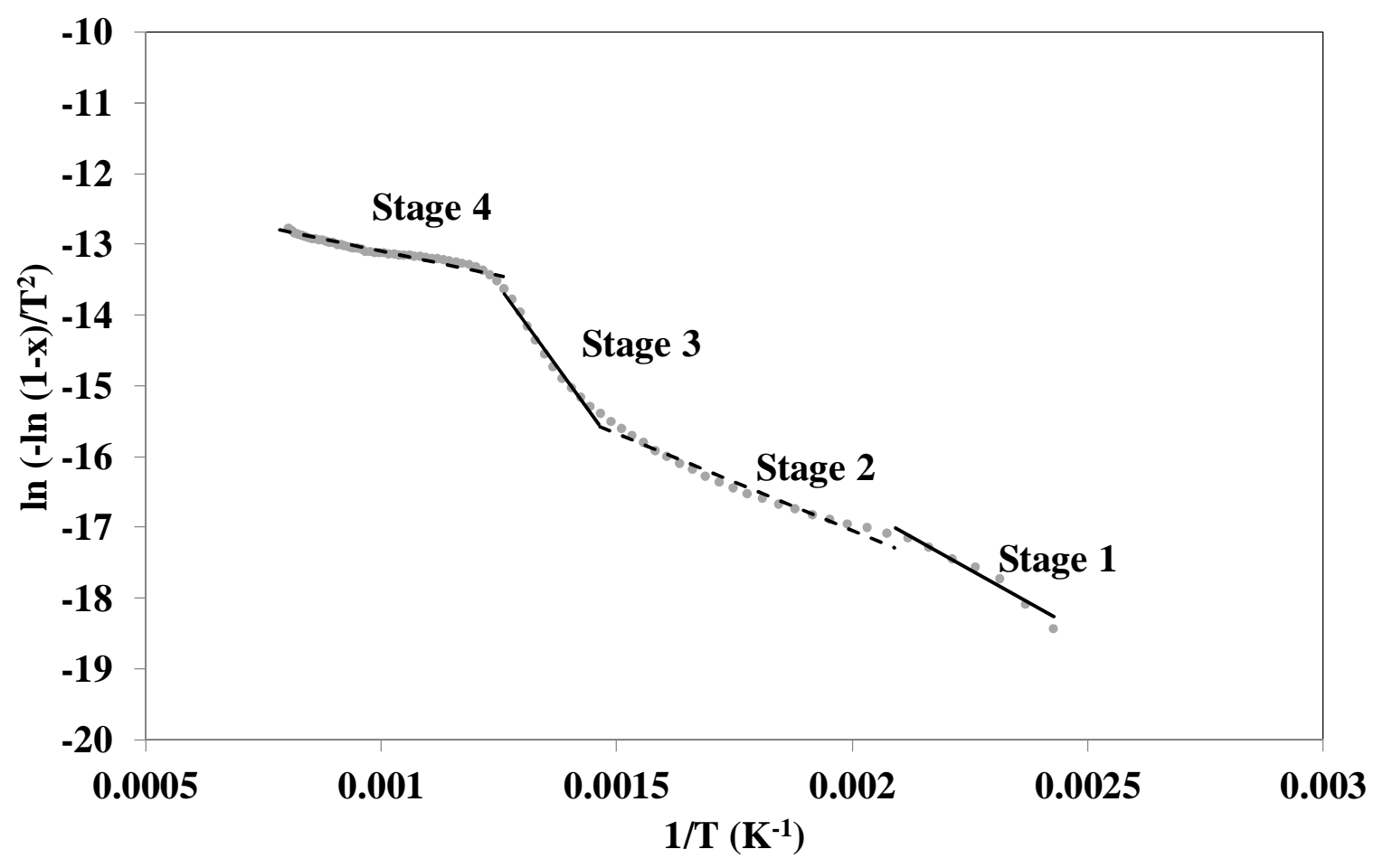


Figure 6. Plots of $\ln \left(-\ln (1-\mathrm{x}) / \mathrm{T}^{2}\right)$ against $1 / \mathrm{T}$ for coal/LDPE and coal/PS mixtures

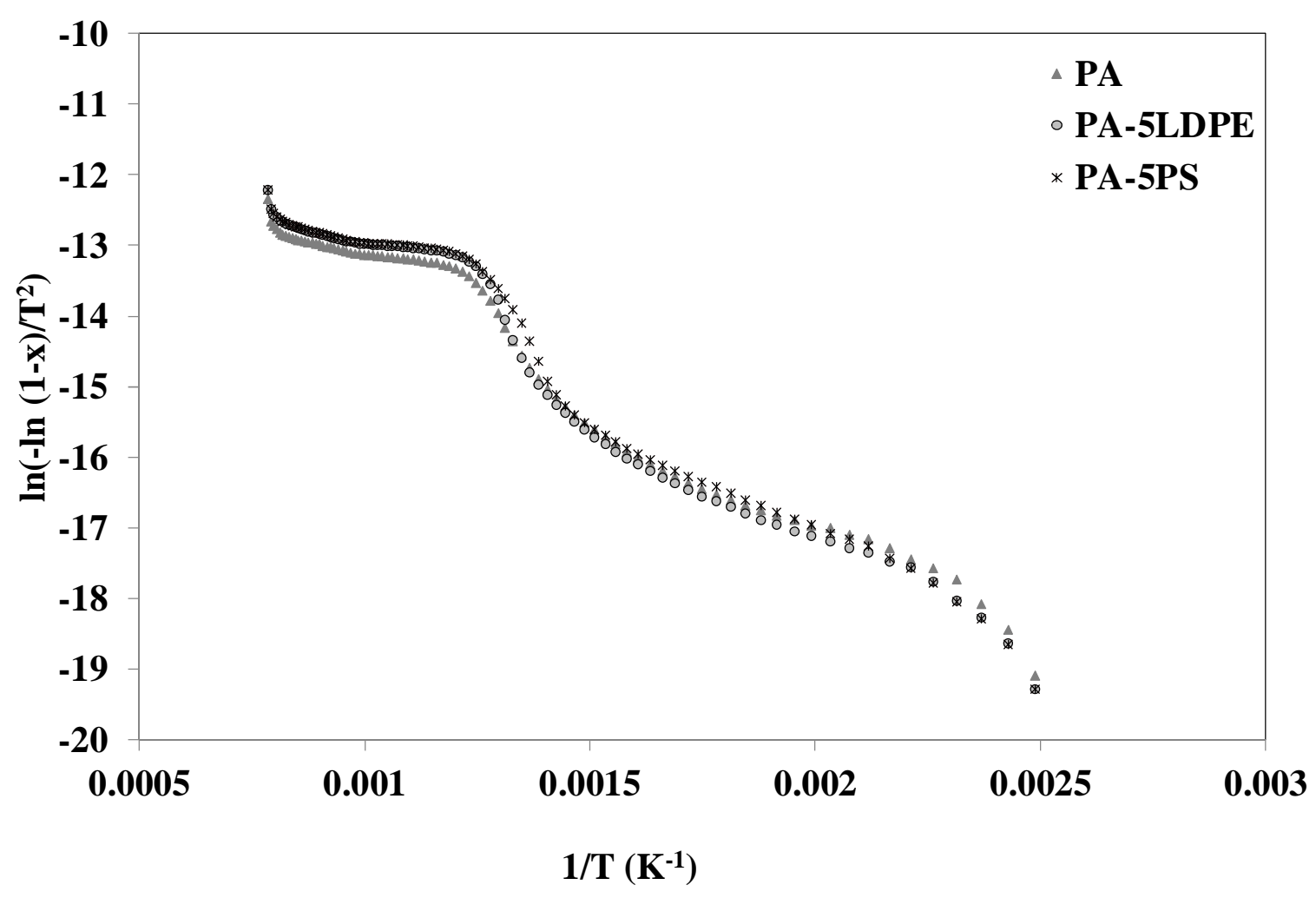


Figure 7. DTG Curve and profile of the ions $\mathrm{m} / \mathrm{z} 2\left(\mathrm{H}_{2}{ }^{+}\right)$and $\mathrm{m} / \mathrm{z} 15\left(\mathrm{CH}_{3}{ }^{+}\right)$of the coal PA.

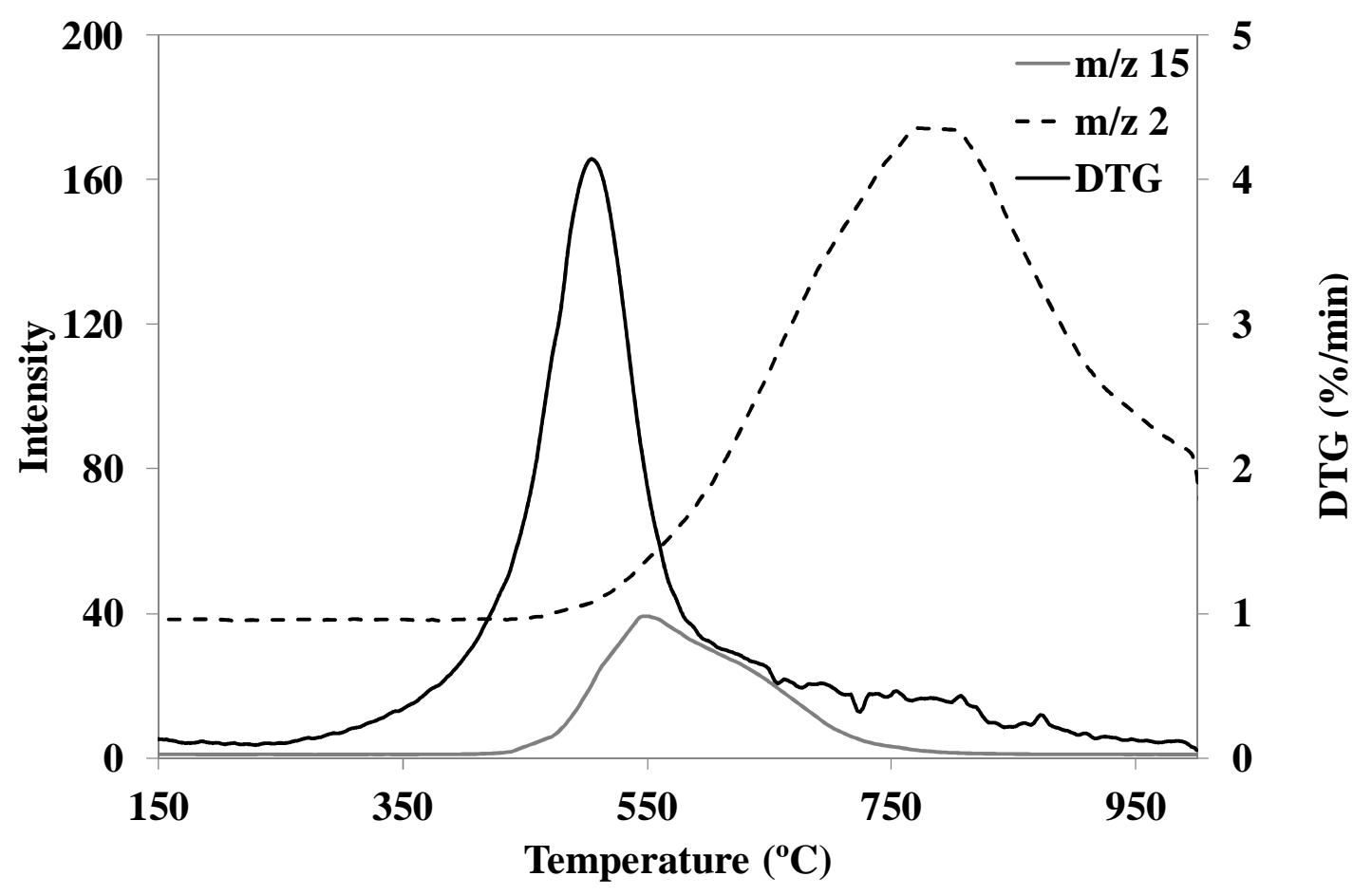


Figure 8. Variation of hydrocarbons evolved during the pyrolysis of the coal blend PA and its mixtures with the different plastic waste
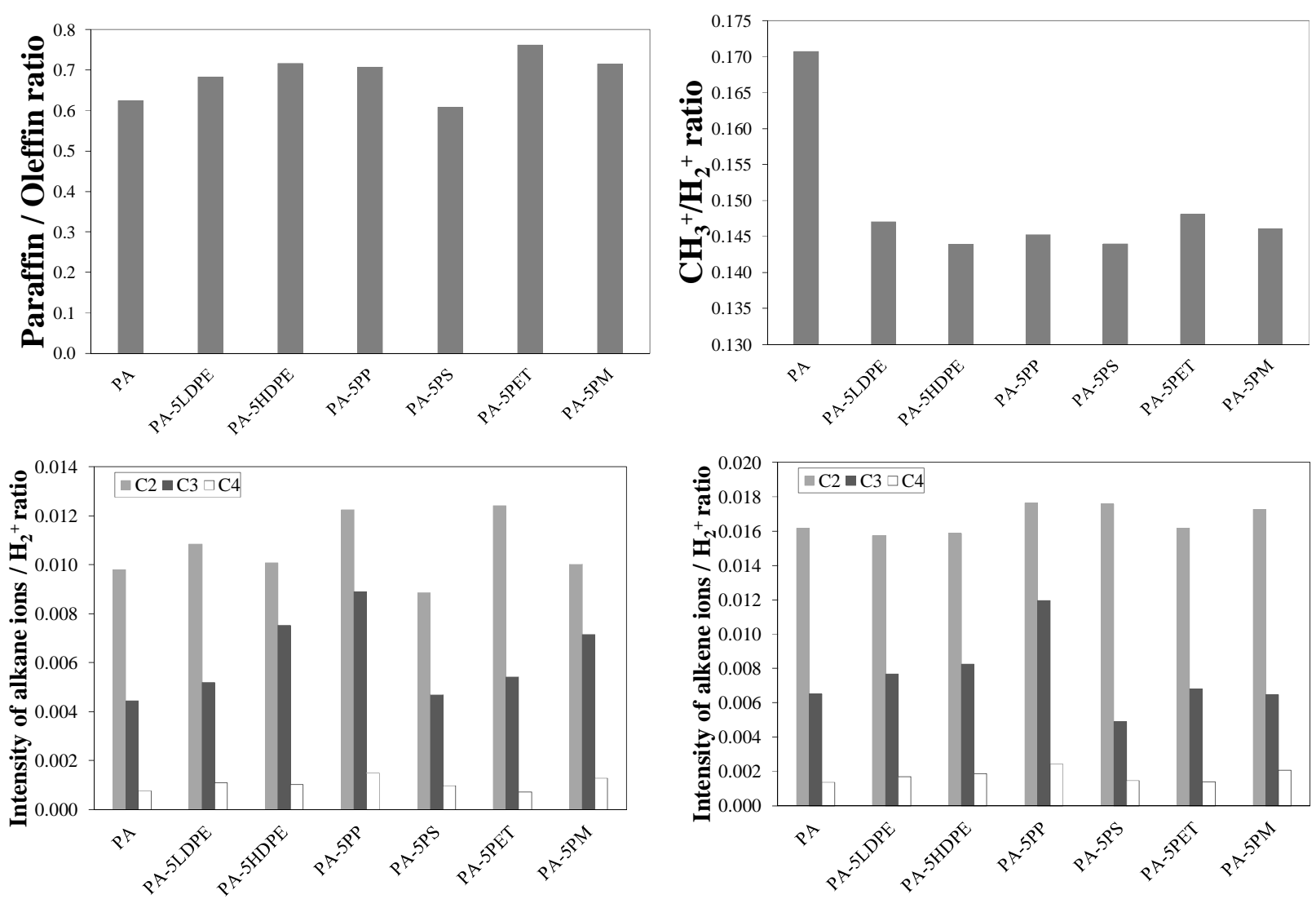
Figure 9. Relations between aliphatic and aromatic fragments for coal/plastic waste mixtures

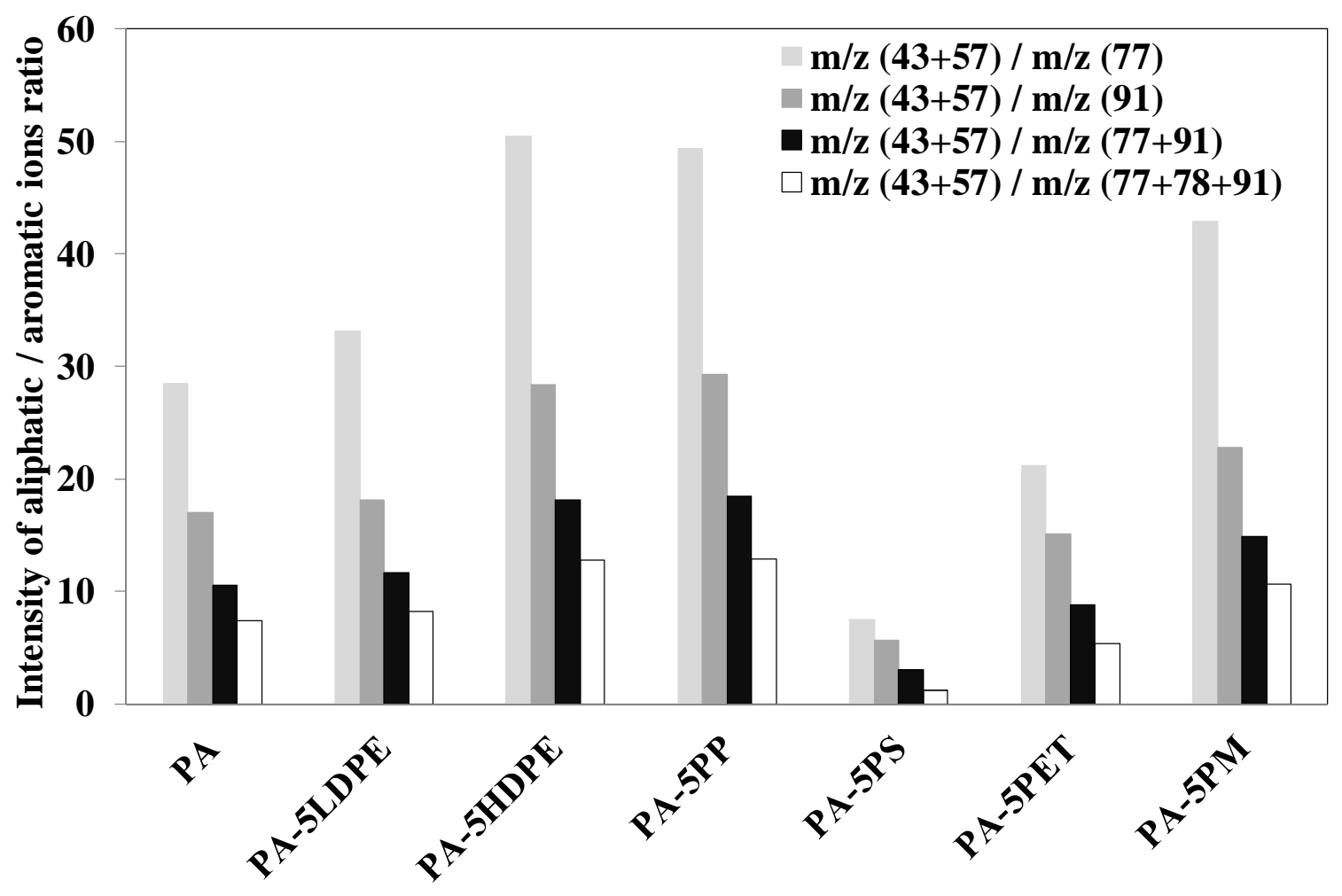


Figure 10. Relations between $\mathrm{CO}_{2}$ and $\mathrm{H}_{2}$ fragments for coal/plastic waste mixtures

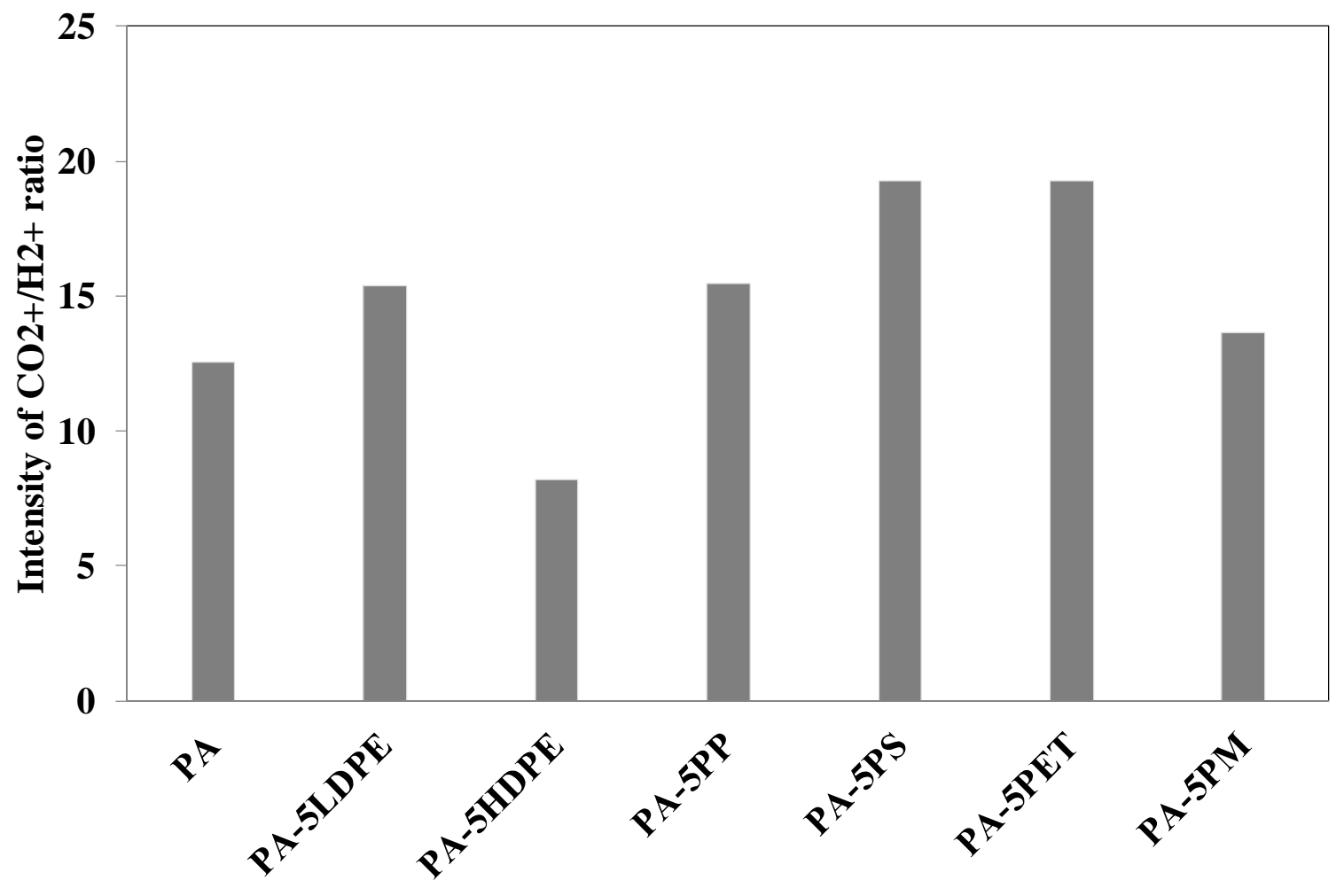


Table 1. Analysis of the coal blend (PA) and plastics studied

\begin{tabular}{|l|cc|ccccc|}
\hline & \multicolumn{3}{|c|}{$\begin{array}{c}\text { Proximate analysis } \\
\text { (wt \% d.b.)* }\end{array}$} & \multicolumn{5}{c|}{$\begin{array}{c}\text { Ultimate analysis } \\
\text { (wt \% d.a.f.)** }\end{array}$} \\
\hline Sample & Ash & Volatile matter & C & H & N & S & O \\
\hline PA & 9.0 & 23.8 & 90.0 & 5.4 & 1.8 & 0.7 & 2.1 \\
LDPE & 4.3 & 92.4 & 81.0 & 14.5 & 0.0 & 0.1 & 0.1 \\
HDPE & 1.0 & 99.1 & 84.4 & 14.2 & 0.1 & 0.0 & 0.3 \\
PP & 0.0 & 97.7 & 85.3 & 14.4 & 0.1 & 0.0 & 0.2 \\
PS & 1.3 & 94.9 & 90.4 & 8.3 & 0.0 & 0.0 & 0.0 \\
PET & $<0.1$ & 82.6 & 63.0 & 4.2 & 0.0 & 0.0 & 32.8 \\
PM & 1.8 & 97.5 & 81.4 & 12.0 & 0.1 & 0.0 & 4.7 \\
\hline
\end{tabular}

*d.b. dry basis; **d.a.f. dry ash free 
Table 2. Thermogravimetric data of plastic samples

\begin{tabular}{|l|cccccc|}
\hline & LDPE & HDPE & PP & PS & PET & PM \\
\hline Ti $\left({ }^{\mathbf{o}} \mathbf{C}\right)^{\mathbf{a}}$ & 436 & 425 & 410 & 380 & 401 & 389 \\
Tf $\left({ }^{\mathbf{o}} \mathbf{C}\right)^{\mathbf{b}}$ & 513 & 512 & 499 & 483 & 503 & 497 \\
Tf-Ti $\left({ }^{\mathbf{o}} \mathbf{C}\right)$ & 77 & 87 & 89 & 103 & 102 & 108 \\
Tmax $\left({ }^{\mathbf{0}} \mathbf{C}\right)^{\mathbf{c}}$ & 490 & 491 & 475 & 441 & 449 & 466 \\
DTG max (\%/min) & 59.3 & 69.8 & 62.9 & 59.5 & 49.7 & 41.8 \\
Residue (\%) & 7.6 & 0.9 & 2.3 & 5.1 & 17.4 & 2.5 \\
\hline
\end{tabular}

${ }^{\text {a }} \mathrm{Ti}$, temperature at $2 \%$ conversion.

${ }^{\mathrm{b}} \mathrm{Tf}$, temperature at $98 \%$ conversion.

${ }^{\mathrm{c}}$ Tmax, temperature of maximum volatile matter released.

${ }^{\mathrm{d}}$ DTGmax, maximum rate of volatile matter evolution. 
Table 3. Thermogravimetric data of coal blend (PA) and coal/plastic samples

\begin{tabular}{|c|c|c|c|c|c|c|c|}
\hline & PA & $-5 \mathrm{LDF}$ & $-5 H D P E$ & PA-5PP & PA-5PS & PA-5PET & PA-5PM \\
\hline $\operatorname{Ti}\left({ }^{\circ} \mathrm{C}\right)$ & 286 & 295 & 312 & 273 & 278 & 299 & 285 \\
\hline $\operatorname{Tf}\left({ }^{\circ} \mathrm{C}\right)$ & 947 & 896 & 907 & 895 & 891 & 912 & 899 \\
\hline Tf-Ti $\left({ }^{\circ} \mathrm{C}\right)$ & 661 & 601 & 595 & 622 & 613 & 613 & 614 \\
\hline $\operatorname{Tmax} 1\left({ }^{\circ} \mathrm{C}\right)$ & - & - & - & - & 461 & 450 & - \\
\hline $\operatorname{Tmax} 2\left({ }^{\circ} \mathrm{C}\right)$ & 505 & 496 & 499 & 495 & 501 & 503 & 499 \\
\hline DTG $\max 1(\% / \mathrm{min})$ & - & - & - & - & 5.2 & 4.0 & - \\
\hline DTG $\max 2(\% / \mathrm{min})$ & 3.9 & 12.8 & 8.1 & 7.7 & 4.4 & 4.1 & 7.6 \\
\hline Residue (\%) & 75.7 & 70.7 & 72.0 & 70.2 & 70.3 & 71.4 & 70.8 \\
\hline
\end{tabular}


Table 4. Kinetic parameters for pyrolysis of plastic studied

\begin{tabular}{|l|cccccc|}
\hline & LDPE & HDPE & PP & PS & PET & PM \\
\hline $\mathbf{E}(\mathbf{k J} / \mathbf{m o l})$ & 314 & 322 & 303 & 247 & 274 & 190 \\
$\mathbf{A}\left(\mathbf{m i n}^{-1}\right)$ & $5.3 \mathrm{E}+22$ & $1.8 \mathrm{E}+23$ & $2.7 \mathrm{E}+22$ & $1.1 \mathrm{E}+19$ & $7.9 \mathrm{E}+20$ & $3.2 \mathrm{E}+14$ \\
$\mathbf{R}^{\mathbf{2}}$ & 0.999 & 0.996 & 0.999 & 0.993 & 0.997 & 0.999 \\
\hline
\end{tabular}


Table 5. Kinetic parameters for pyrolyisis of coal blend (PA) and coal/plastic mixtures

\begin{tabular}{|c|c|c|c|c|}
\hline Sample & Temperature $\left({ }^{\circ} \mathrm{C}\right)$ & E (kJ/mol) & $\mathbf{A}\left(\mathbf{m i n}^{-1}\right)$ & $\mathbf{R}^{2}$ \\
\hline \multirow{4}{*}{ PA } & $125-210$ & 56 & $2.9 \mathrm{E}+07$ & 0.979 \\
\hline & $215-409$ & 59 & $2.9 \mathrm{E}+05$ & 0.983 \\
\hline & $414-525$ & 194 & $2.1 \mathrm{E}+14$ & 0.983 \\
\hline & $530-986$ & 28 & $2.7 \mathrm{E}+01$ & 0.960 \\
\hline \multirow{4}{*}{ PA-5LDPE } & $125-210$ & 54 & $2.0 \mathrm{E}+07$ & 0.989 \\
\hline & $216-409$ & 57 & $1.9 \mathrm{E}+05$ & 0.985 \\
\hline & $413-519$ & 212 & $4.3 \mathrm{E}+15$ & 0.985 \\
\hline & $523-978$ & 30 & $5.5 \mathrm{E}+01$ & 0.964 \\
\hline \multirow{4}{*}{ PA-5HDPE } & $125-205$ & 52 & $1.1 \mathrm{E}+07$ & 0.987 \\
\hline & $212-409$ & 60 & $3.9 \mathrm{E}+05$ & 0.988 \\
\hline & $415-519$ & 211 & $3.0 \mathrm{E}+15$ & 0.991 \\
\hline & $520-978$ & 28 & $3.9 \mathrm{E}+01$ & 0.972 \\
\hline \multirow{4}{*}{ PA-5PP } & $125-205$ & 52 & $1.0 \mathrm{E}+07$ & 0.982 \\
\hline & $212-409$ & 50 & $4.2 \mathrm{E}+04$ & 0.981 \\
\hline & $413-520$ & 213 & $4.4 \mathrm{E}+15$ & 0.988 \\
\hline & $525-998$ & 30 & $5.0 \mathrm{E}+01$ & 0.981 \\
\hline \multirow{4}{*}{ PA-5PS } & $125-210$ & 56 & $2.7 \mathrm{E}+07$ & 0.987 \\
\hline & $215-404$ & 51 & $3.5 \mathrm{E}+04$ & 0.986 \\
\hline & $414-519$ & 170 & $3.3 \mathrm{E}+12$ & 0.981 \\
\hline & $526-998$ & 39 & $1.7 \mathrm{E}+02$ & 0.985 \\
\hline \multirow{4}{*}{ PA-5PET } & $125-210$ & 54 & $1.9 \mathrm{E}+07$ & 0.975 \\
\hline & $215-404$ & 57 & $1.6 \mathrm{E}+05$ & 0.988 \\
\hline & $414-519$ & 163 & $1.7 \mathrm{E}+12$ & 0.971 \\
\hline & $526-998$ & 27 & $3.5 \mathrm{E}+01$ & 0.988 \\
\hline \multirow{4}{*}{ PA-5PM } & $125-210$ & 57 & $3.9 \mathrm{E}+07$ & 0.977 \\
\hline & $215-404$ & 55 & $1.2 \mathrm{E}+05$ & 0.987 \\
\hline & 414-519 & 209 & $2.2 \mathrm{E}+15$ & 0.987 \\
\hline & $520-978$ & 28 & $4.1 \mathrm{E}+01$ & 0.985 \\
\hline
\end{tabular}


Table 6. Ion fragments monitored by TG-MS analysis

\begin{tabular}{|l|l|}
\hline $\mathbf{m} / \mathbf{z}$ & Assignment \\
\hline 2 & $\mathrm{H}_{2}^{+}$ \\
15 & $\mathrm{CH}_{3}{ }^{+}$ \\
$29,43,57$ & Alkane series: $\mathrm{C}_{2} \mathrm{H}_{5}{ }^{+}, \mathrm{C}_{3} \mathrm{H}_{7}{ }^{+}, \mathrm{C}_{4} \mathrm{H}_{9}{ }^{+} \ldots \mathrm{C}_{\mathrm{n}} \mathrm{H}_{2 \mathrm{n}+1}{ }^{+}$ \\
$27,41,55$ & Alkene series: $\mathrm{C}_{2} \mathrm{H}_{3}{ }^{+}, \mathrm{C}_{3} \mathrm{H}_{5}{ }^{+}, \mathrm{C}_{4} \mathrm{H}_{7}{ }^{+} \ldots \mathrm{C}_{\mathrm{n}} \mathrm{H}_{2 \mathrm{n}-1}{ }^{+}$ \\
$77,78,91$ & Aromatic series: $\mathrm{C}_{6} \mathrm{H}_{5}{ }^{+}, \mathrm{C}_{6} \mathrm{H}_{6}{ }^{+}, \mathrm{C}_{7} \mathrm{H}_{7}{ }^{+}$ \\
44 & $\mathrm{CO}_{2}^{+}$ \\
\hline
\end{tabular}


Table 7. Maximum evolution temperature for the ion fragments monitored.

\begin{tabular}{|c|c|c|c|c|c|c|c|}
\hline & $\mathbf{P A}$ & $\begin{array}{c}\text { PA- } \\
\text { 5LDPE }\end{array}$ & $\begin{array}{c}\text { PA- } \\
\text { 5HDPE }\end{array}$ & $\begin{array}{l}\text { PA- } \\
5 P P\end{array}$ & $\begin{array}{l}\text { PA- } \\
\text { 5PS }\end{array}$ & $\begin{array}{l}\text { PA- } \\
\text { 5PET }\end{array}$ & $\begin{array}{l}\text { PA- } \\
\text { 5PM }\end{array}$ \\
\hline $\operatorname{Tmax} \mathrm{m} / \mathrm{z} 2$ & 786 & 786 & 782 & 785 & 788 & 780 & 789 \\
\hline $\operatorname{Tmax} \mathrm{m} / \mathrm{z} 15$ & 549 & 547 & 544 & 548 & 543 & 553 & 546 \\
\hline $\operatorname{Tmax} \mathbf{m} / z 29$ & 511 & 507 & 502 & 505 & 503 & 508 & 506 \\
\hline $\operatorname{Tmax} \mathrm{m} / \mathrm{z} 43$ & 503 & 504 & 502 & 503 & 503 & 503 & 504 \\
\hline Tmax m/z 57 & 501 & 501 & 499 & 498 & 498 & 503 & 504 \\
\hline Tmax m/z 27 & 516 & 512 & 509 & 505 & 516 & 513 & 509 \\
\hline $\operatorname{Tmax} \mathrm{m} / \mathrm{z} 41$ & 503 & 504 & 504 & 500 & 508 & 508 & 508 \\
\hline $\operatorname{Tmax} \mathrm{m} / \mathrm{z} 55$ & 501 & 504 & 502 & 498 & 503 & 503 & 501 \\
\hline Tmax m/z 77 & 508 & 512 & 512 & 508 & 471 & 503 & 509 \\
\hline $\operatorname{Tmax} \mathrm{m} / \mathrm{z} 78$ & 529 & 527 & 522 & 520 & 466 & 508 & 556 \\
\hline $\operatorname{Tmax} \mathbf{m} / \mathbf{z} 91$ & 518 & 524 & 527 & 520 & 468 & 518 & 529 \\
\hline $\operatorname{Tmax} 1 \mathrm{~m} / \mathrm{z} 44$ & 353 & - & - & - & - & 465 & - \\
\hline $\operatorname{Tmax} 2 \mathrm{~m} / \mathrm{z} 44$ & 508 & 519 & 517 & 513 & 518 & 633 & 529 \\
\hline $\operatorname{Tmax} 3$ m/z 44 & - & 687 & 642 & 660 & 696 & 698 & 674 \\
\hline
\end{tabular}


[1] P.T. Williams, E. Slaney, Analysis of products from the pyrolysis and liquefaction of single plastics and waste plastic mixtures, Resources, Conservation and Recycling 51 (2007) 754769.

[2] W. Chunfei, P.T. Williams, Pyrolysis-gasification of post-consumer municipal solid plastic waste for hydrogen production, International Journal of Hydrogen Energy 35 (2010) 949-957. [3] P. Straka, O. Bicakova, Hydrogen-rich gas a product of two stage co-gasification of lignite/waste plastic mixtures, International Journal of Hydrogen Energy 39 (2014) 1098710995.

[4] S. Melendi, C. Barriocanal, R. Alvarez, M.A. Diez, Influence of low-density polyethylene addition on coking pressure, Fuel 119 (2014) 274-284.

[5] R. Sakurovs, Interactions between coking coals and plastics during co-pyrolysis, Fuel 82 (2003) 1911-1916.

[6] S. Nomura, K. Kato, The effect of plastic size on coke quality and coking pressure in the co-carbonization of coal-plastic in coke oven, Fuel 85 (2006) 47-56.

[7] M.A. Diez, R. Alvarez, C.S. Canga, C. Barriocanal, F. Gayo, A. Dominguez, Cocarbonization of coal with LDPE and HDPE plastic waste at three different scales, Eurocarbon II (2000) 717-718.

[8] K. Kato, S. Nomura, H. Uematsu, Development of waste plastics recycling process using coke ovens, ISIJ International 42 (2002) S10.

[9] S. Nomura, K. Kato, Basic study on separate charge of coal and waste plastics in coke oven chamber, Fuel 84 (2005) 429-435.

[10] S. Melendi, M.A. Diez, R. Alvarez, C. Barriocanal, Plastic wastes, lube oils and carbochemical products as secondary feedstocks for blast-furnace coke production, Fuel Processing Technology 92 (2011) 471-478.

[11] S. Melendi, M.A. Diez, R. Alvarez, C. Barriocanal, Relevance of the composition of municipal plastic wastes for metallurgical coke production, Fuel 90 (2011) 1431-1438.

[12] M.A. Diez, R. Alvarez, S. Melendi, C. Barriocanal, Feedstock recycling of plastic wastes/oil mixtures in cokemaking, Fuel 88 (2009) 1937-1944. 
[13] L. Vivero, C. Barriocanal, R. Alvarez, M.A. Diez, Effects of plastic wastes on coal pyrolysis behavior and the structure of semicokes, J. Anal. Appl. Pyrolysis 74 (2005) 327-336.

[14] S. Nomura, K. Kato, T. Nakagawa, I. Komaki, The effect of plastic addition on coal caking properties during carbonization, Fuel 82 (2003) 1775-1782.

[15] A. Dominguez, C.G. Blanco, C. Barriocanal, R. Alvarez, M.A. Diez, Gas chromatographic study of the volatile products from co-pyrolysis of coal and polyethylene wastes, J. Chromatography A 918 (2001) 135-144.

[16] L. Zhou, T. Luo, Q. Huang, Co-pyrolysis characteristics and kinetics of coal and plastic blends, Energy Conversion and Management 50 (2009) 705-710.

[17] S. Sharma, A.K. Ghoshal, Study of kinetics of co-pyrolysis of coal and waste LDPE blends under argon atmosphere, Fuel 89 (2010) 3943-3951.

[18] C. Barriocanal, M.A. Diez, R. Alvarez, M.D. Casal, C.S. Canga, On the relationship between coal plasticity and thermogravimetric analysis, Journal of Analytical and Applied Pyrolysis 67 (2003) 23-40.

[19] E. Díaz-Faes, C. Barriocanal, M.A. Diez, R. Alvarez, Applying TGA parameters in coke quality prediction models, Journal of Analytical and Applied Pyrolysis 79 (2007) 154-160.

[20] R. Loison, P. Foch, A. Boyer Coke quality and production. London: Butterwoth; 1989.

[21] P.R. Solomon, M.A. Serio, R.M. Carangelo, J.R. Markham, Very rapid coal pyrolysis, Fuel 65 (1986) 182-184.

[22] G.P. Ying, V. Enrique, P. Luis, Pyrolysis of blends of biomass with poor coals, Fuel 75 (1996) 412-418.

[23] V.K. Mustafa, O. Esber, K. Ozgen, H. Cahit, Effect of particle size on coal pyrolysis, Journal of Analytical and Applied Pyrolysis 45 (1998) 103-110.

[24] B. Enrico, L. Federica, P. Luigi, T. Leonardo, Devolatilization rate of biomasses and coalbiomass blends: an experimental investigation, Fuel 81 (2002) 1041-1050.

[25] Q.R. Liu, H.Q. Hu, Q. Zhou, S.W. Zhu, G.H. Chen, Effect of inorganic matter on reactivity and kinetics of coal pyrolysis, Fuel 83 (2004) 713-718.

[26] L. Zhoua, Y. Wanga, Q. Huanga, J. Cai, Thermogravimetric characteristics and kinetic of plastic and biomass blends co-pyrolysis, Fuel Processing Technology 87 (2006) 963-969. 
[27] M.N. Siddiqui, H.H. Redhwi, Pyrolysis of mixed plastics for the recovery of useful products, Fuel Processing Technology 90 (2009) 545-552.

[28] M.A. Diez, C. Barriocanal, R. Alvarez. Plastic wastes as modifiers of the thermoplasticity of coal, Energy and Fuels 19 (2005) 2304-2316.

[29] M. Castro-Díaz, L. Edecki, K.M. Steel, J.W. Patrick, C.E.Snape, Determination of the effects caused by different polymers on coal fluidity during carbonization using hightemperature 1H NMR and rheometry, Energy \& Fuels 22 (2008) 471-479.

[30] R. Miranda, H. Pakdel, C. Roy, C. Vasile, Vacuum pyrolysis of commingled plastics containing PVC II, Product analysis Polymer Degradation and Stability 73 (2001) 47-67.

[31] K.H. Van Heek, W Hodek, Structure and pyrolysis behaviour of different coals and relevant model substances, Fuel 73 (1994) 886-896.

[32] E.S. Uzumkesici, M.D. Casal, C. Mc Rae, C.E. Snape, D. Taylor, Co-processing of single plastic waste stream in low temperature carbonisation, Fuel 78 (1999) 1697-1702.

[33] J.D. Martinez, N. Puy, R. Murillo, T. Garcia, M.V. Navarro, A.M. Mastra, Waste tyre pyrolysis - A review, Renewable and Sustainable Energy Reviews 23 (2013) 179-213. 


\section{Highlights}

Plastics thermal degradation varies according to its structure and composition A synergistic effect exists between coal and individual plastic wastes

Evolution of the plastics volatile matter is delayed when they are blended with coal

There is agreement between compound chemical families and coal fluidity modifications 